\title{
CareQuest $^{\mathbb{C}}$
}

Institute for Oral Health

\section{astdd}

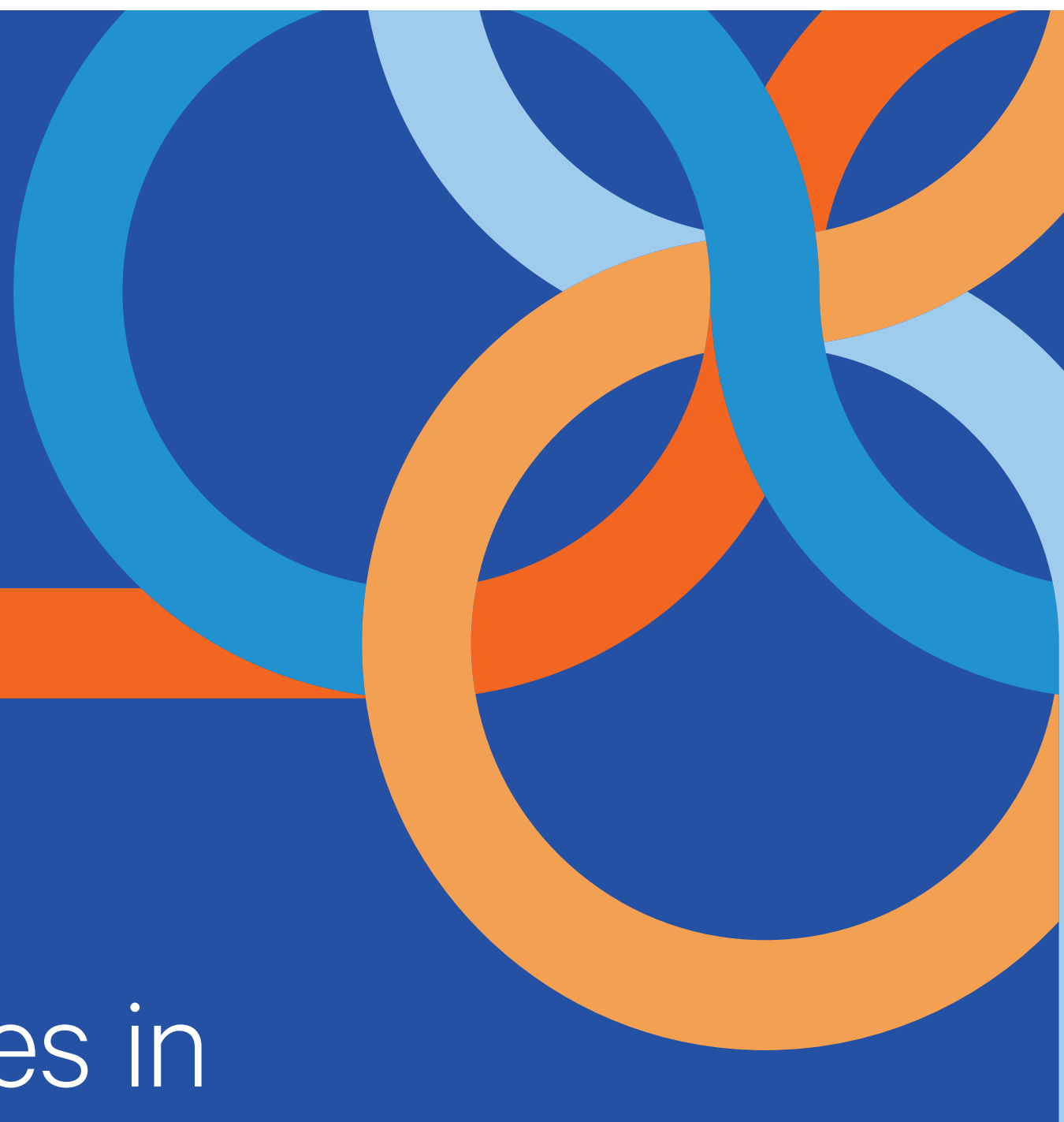

Implementing School-Based Oral Health Programs:

Short- and Long-Term Impact of COVID-19 


\section{Authors}

Tamanna Tiwari, MPH, MDS, BDS

Assistant Professor, Department of Community Dentistry and

Population Health

Associate Director, Center for Oral Disease Prevention and Population

Health Research,

University of Colorado School of Dental Medicine

Lori Kepler Cofano, RDH, BSDH

Dental Public Health Consultant

Association of State and Territorial Dental Directors

Chris Wood, RDH, BS

Executive Director

Association of State and Territorial Dental Directors

Julie Frantsve-Hawley, PhD, CAE

Director, Analytics and Evaluation

CareQuest Institute for Oral Health

\section{Reviewers}

ASTDD School-based Programs Workgroup members 


\section{Challenges faced by State and Territorial Dental Directors}

The pandemic continues to threaten oral health programs for several reasons. State and territorial Oral Health Program directors reported that $16 \%$ of their time was taken away from state oral health program activities to support COVID-19related activities for the state. There was a lack of uniformity on how the dental directors spent their time on activities to support COVID-19 and their regular oral health program activities.

Seventy percent of the dental directors said they had conducted a needs assessment of oral health programs to understand the effect of COVID-19 school shutdowns and, in particular, how SBOHPs were affected. These assessments were conducted in several different ways: $40 \%$ were conducted using email and phone calls, 34\% were conducted through virtual meetings, and $22 \%$ used a survey format for the needs assessment that was sent via emails. Most of the needs assessments were completed by school-based sealant providers, sealant managers, school-based dental hygienists, and other school-based providers. Most of the dental directors who reported that they did not conduct a needs assessment indicated that it was because they lacked the personnel for survey implementation and data analysis.

On a more positive note, none of the dental directors reported that SBOHP funding for 2020-2021 was entirely threatened because of COVID-19, and $65 \%$ said it was not at all threatened.

\section{Time Allocation of Dental Director}

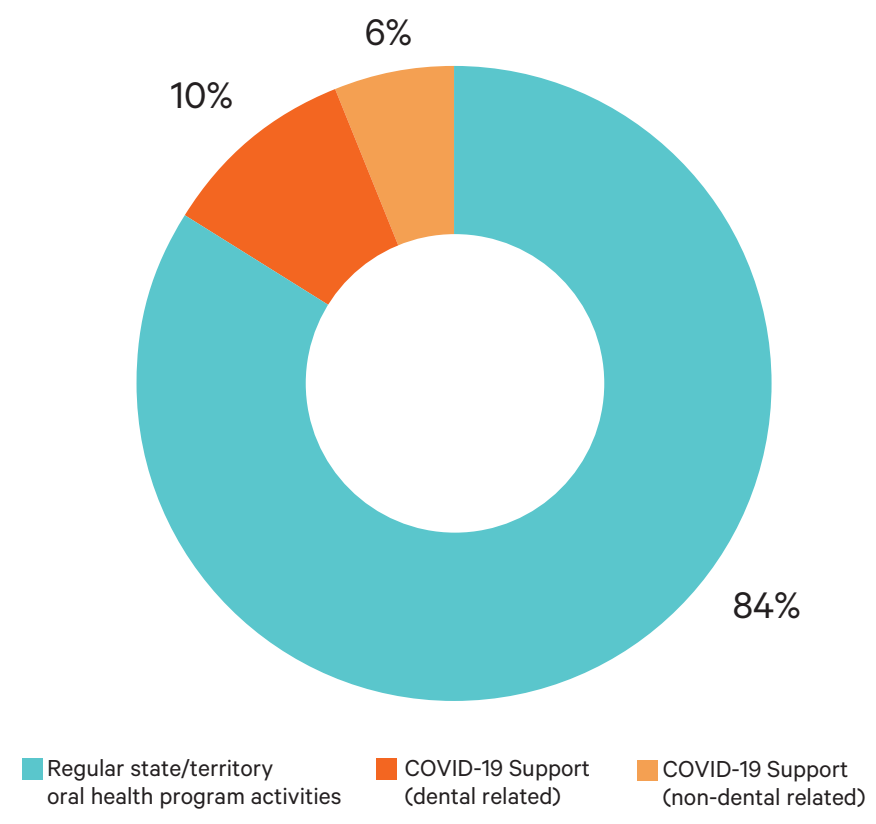
State/Territory Run, Funded or Partnered School-Based Oral
Health Programs' Funding Threatened Due to COVID-19

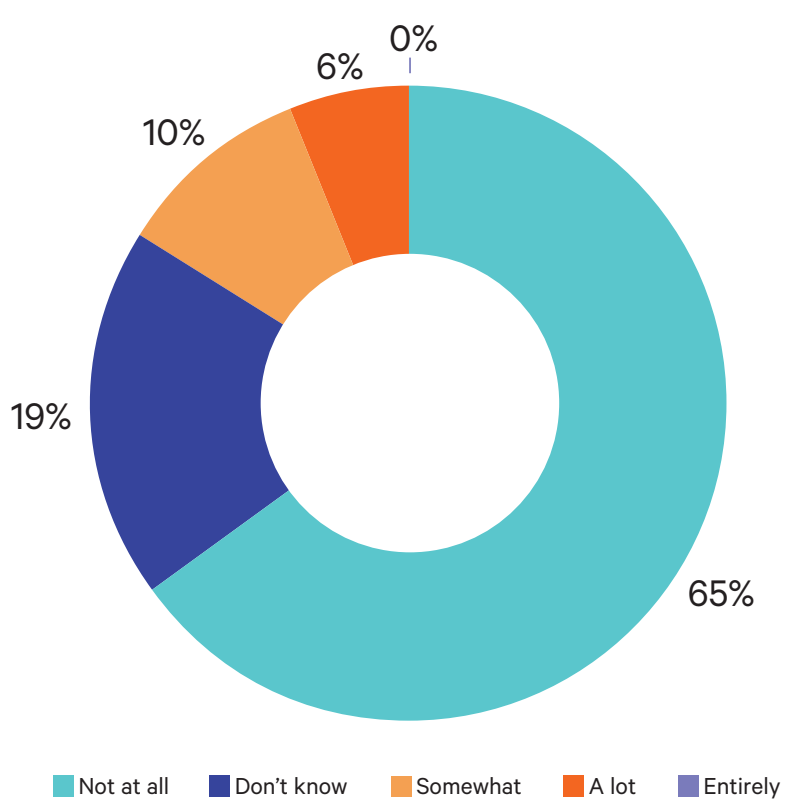




\section{Challenges Faced by SBOHPs Because of the COVID-19 Pandemic}

Apart from oral health screening, SBOHPs provide several preventive services for children, such as fluoride varnish applications and sealant programs. These preventive programs are imperative in preventing and controlling tooth decay in school children and improving children's oral health.

SBOHPs faced many challenges during 2020 as a result of the COVID crisis. These new and ongoing challenges may persist for years once the pandemic has ended. Several oral health programs, including Basic Screening Survey (BSS), sealant programs, and fluoride varnish programs were significantly impacted during the 2020-2021 school year. The BSS is a tool that provides state and local health authorities with a consistent model for measuring oral disease. Both the planning and implementation of these programs were affected. Only 25\% of SBOHPS were both planned and implemented in both Fall 2020 and Spring 2021.

There were slight improvements seen for planned oral health programs in Spring 2021. Although the school sealant programs are still running at $25 \%$ capacity, the percentage of lesson plans on oral health provided by schools has improved from 18\% to 20\% from the Fall 2020 to Spring 2021.
Most of these programs were implemented within school buildings. Only $7 \%$ of school-based sealant programs were conducted on school grounds outside the school building. None of the activities, such as fluorive varnish application or screenings, were operated using a drive-through program.

Further inquiry led to reporting about the underlying reasons why some schools could restart oral health programs successfully. It was not surprising to see that school administration and school nurses' support and cooperation were the dental directors' highlighted reasons for the restart of programs both in Fall 2020 and Spring 2021. Dental directors noted that supportive funding sources were an essential factor in the restart of oral health programs in schools.

Most of the dental directors mentioned that they had established long-standing relationships with school administration, staff, and school nurses, which has led to a greater understanding of the importance of oral health prevention programs. Transparency on the part of school administration and education on infection prevention and control encouraged parents to give their consent for these programs. Dental directors also reported that dental hygienists and assistants were in frequent communication with parents.

Planning and Implementation of School-Based Oral Health Programs

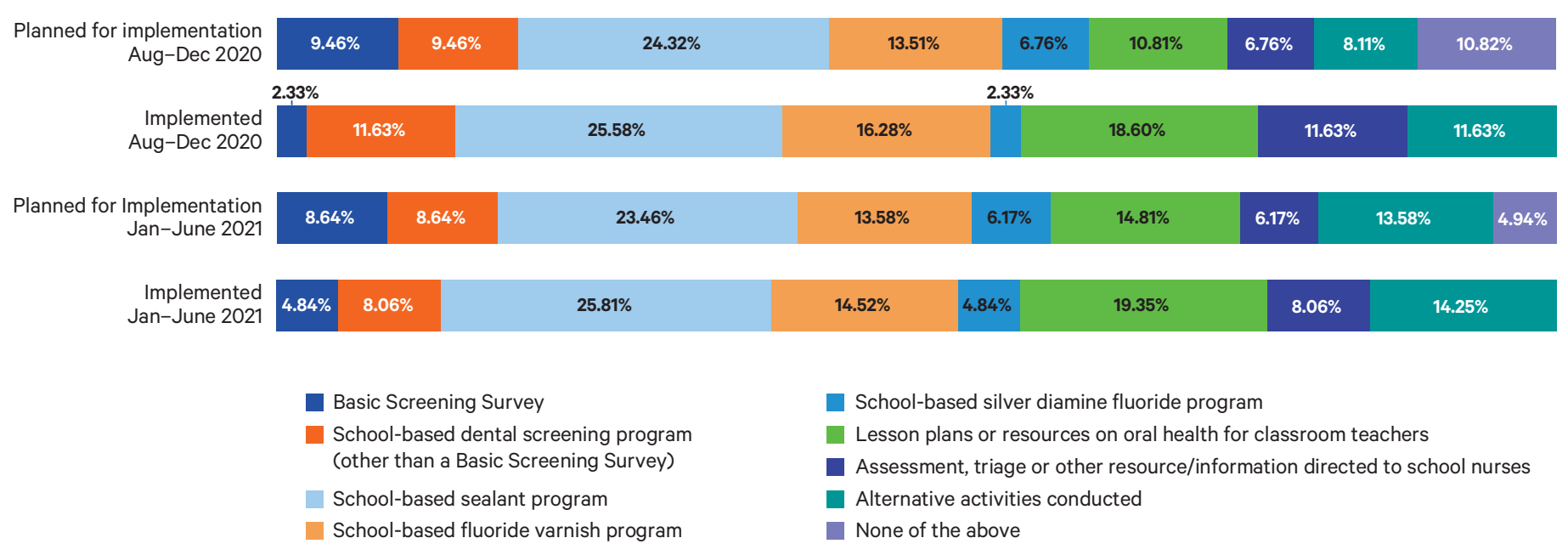




\section{Support for Restarting School-Based Oral Health Program}

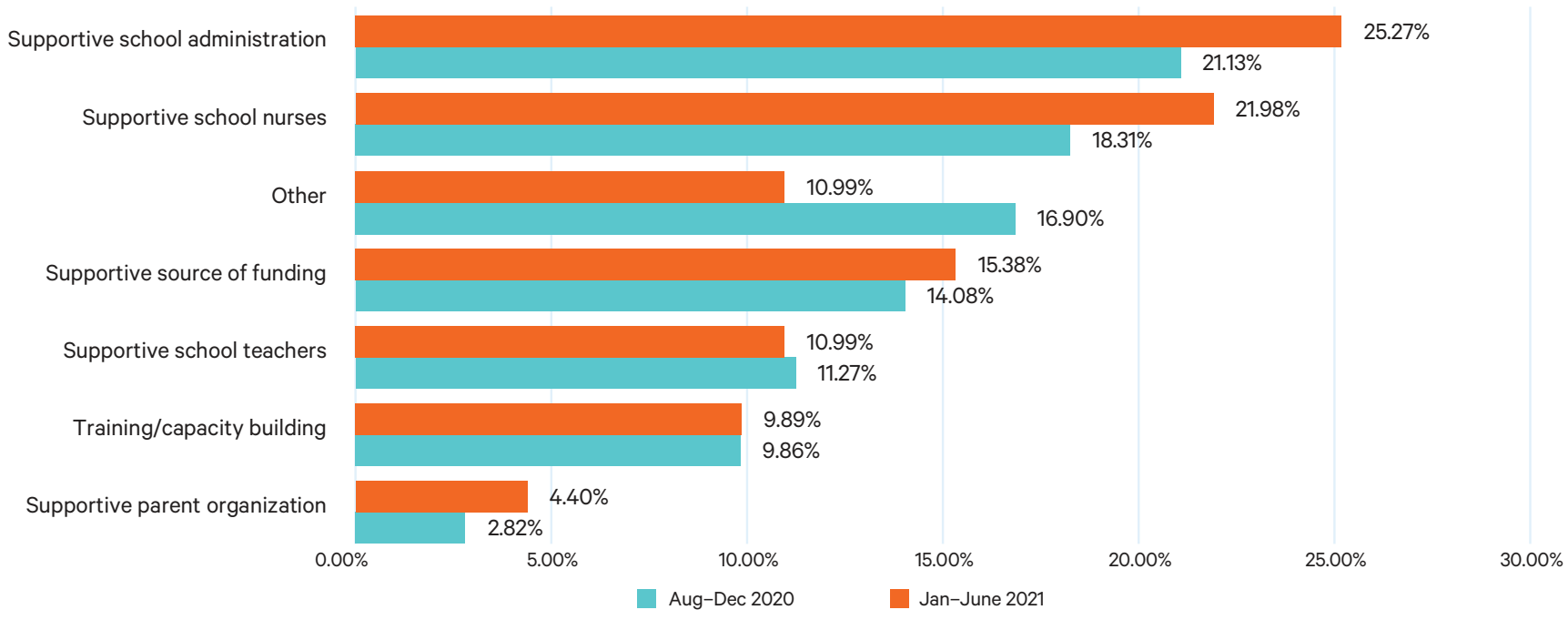

When the schools were using virtual learning, several oral health program activities, such as case management and caregiver education on oral health behaviors, also were conducted virtually.

Some dental directors discussed reasons why schools were not participating in SBOHPs. About one-quarter of dental directors reported concern about COVID-19 spread during the AugustDecember 2020 and January-June 2021 reporting periods. Several other reasons were reported, including schools using remote/virtual learning, staff and parents not being ready, the constant changes in policies at the school district level, and local policy changes. It is interesting to see a slight shift in the underlying reasons for schools not participating in SBOHPs between August-December 2020 and January-June 2021. Under the "Other" category, dental directors reported that many schools consider SBOHP staff to be visitors based on school rules, and because of this they were not allowed into the schools. In addition, health departments reassigned staff to vaccine clinics or other COVID-19 related work, which took them away from conducting the oral health program.

\section{Reasons Some Schools Did Not Participate in Oral Health Programs}

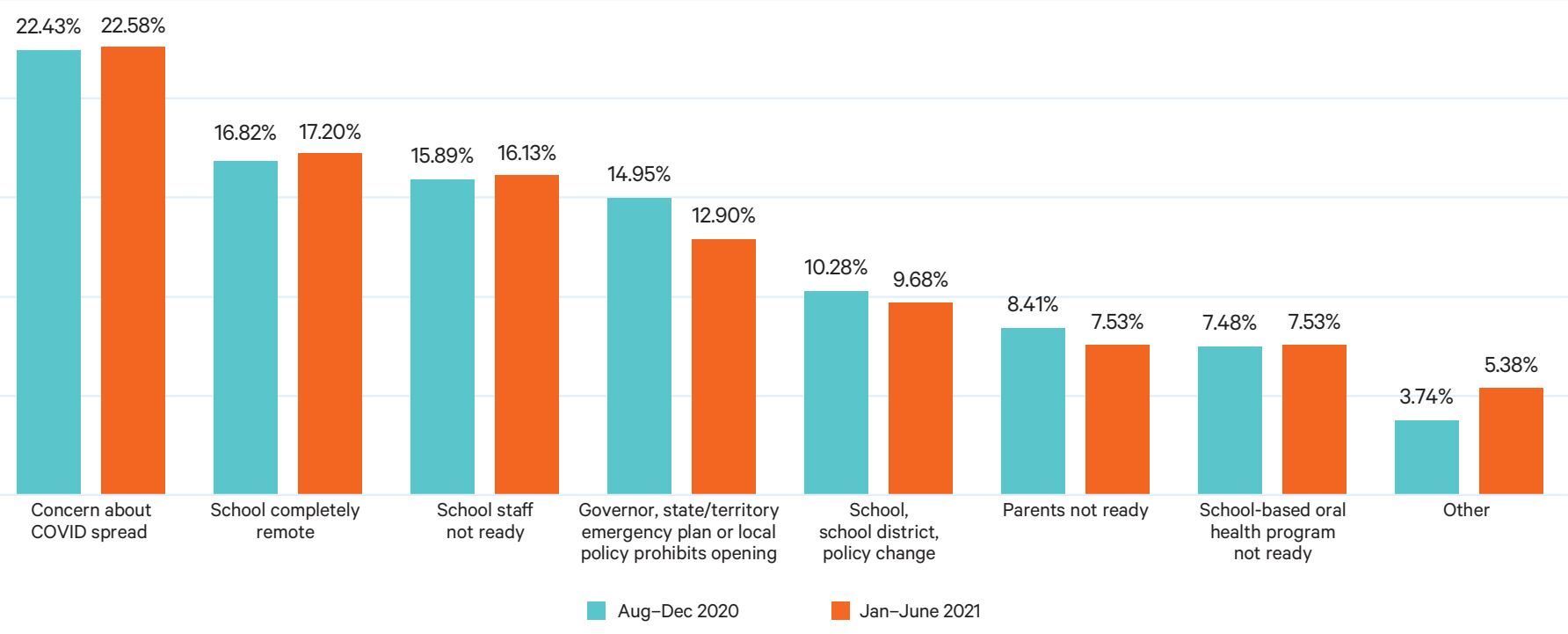




\section{Challenges Anticipated by SBOHPs in the Coming Years}

Dental directors were asked about planning for oral health programs for the 2021-2022 school year. Only 25\% said they were planning school-based sealant programs, and $16 \%$ were planning school-based fluoride varnish programs or a BSS. These figures are similar to the ones for the 2020-2021 school year. About $16 \%$ of dental directors reported that they were planning BSS in the 2021-2022 school year. That was better than the 2020-2021 planning figures, which were about 9\%. One percent of the dental directors were not planning any oral health programs in 2021-2022. These results show a high level of uncertainty that dental directors and their staff face in planning school-based oral health screening and prevention programs. There are several unknown factors about schools reopening for in-person learning, and readiness of schools, staff, and parents who need to be engaged in these programs.

The survey included a question to understand the challenges related to the measurement of dental diseases. Specifically, dental directors were asked whether they would be able to implement a BSS within their typical 5-year cycle, and if not, would their data be older than five years?

At the school level, the BSS is conducted in elementary schools and Head Start programs. Most states conduct a BSS in elementary schools. However, not every state conducts a BSS in Head Start programs; 31 states have conducted a BSS in Head Start programs in past. Thirty-six percent of the dental directors responded that the elementary school BSS data would be 5 years old in 2023, and $24 \%$ said the same for their Head Start BSS data. These results show that there could be a lack of current dental disease measurements in the coming years, which could have serious policy and funding implications.

\section{Oral Health Programs Planned for 2021-2022}

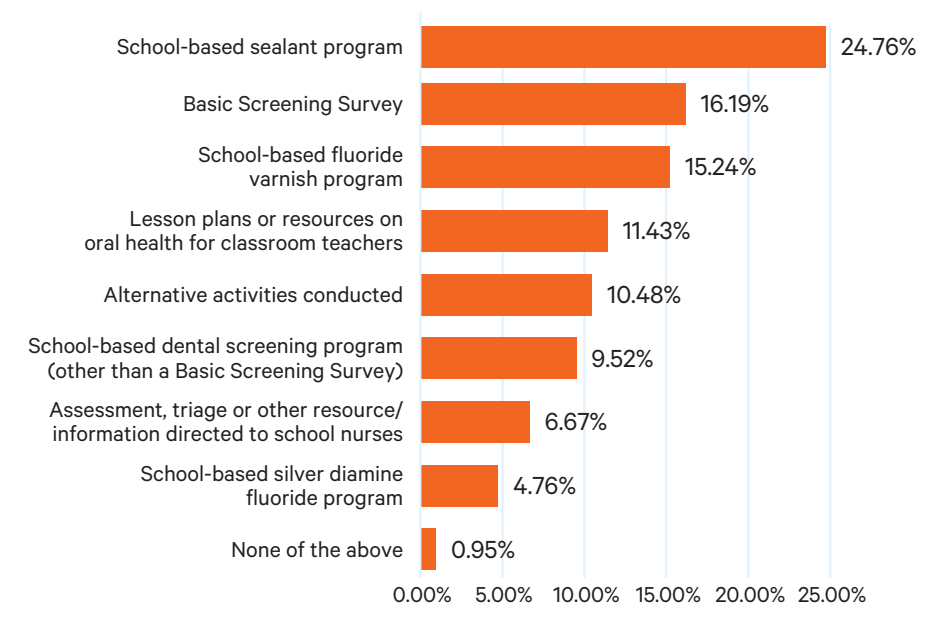

Will the BSS Data Be Older than 5 Years in 2023?

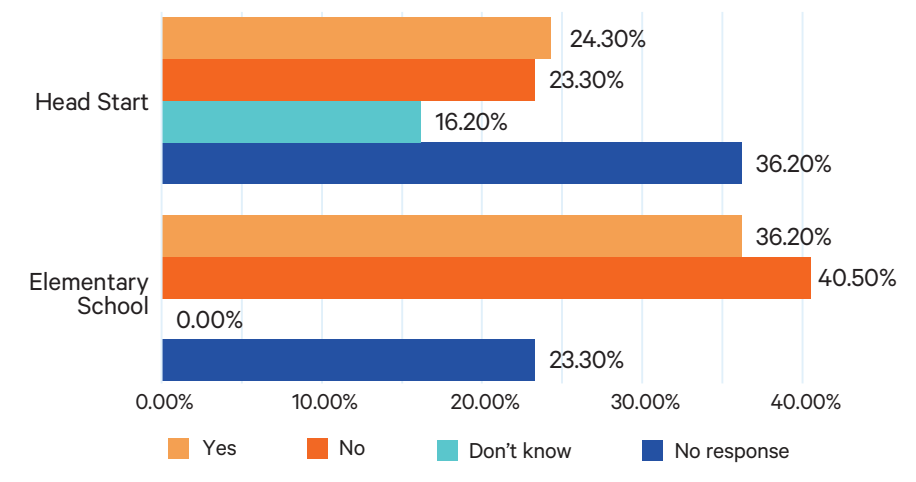




\section{Additional Support from State/Territorial Oral Health Programs for Schools}

Sixty-five percent of dental directors were confident they could provide additional support to school-based programs to increase readiness to participate in oral health programs, and $16 \%$ indicated that they may be able to provide support. The support that they would provide could include additional personal protective equipment (PPE), educational materials, infection prevention training, and COVID protocols. Dental directors commented that several school-based programs asked for assistance in adding COVID-19 related information to consent forms and other documents that are sent to parents.

\section{Support to Increase Readiness}

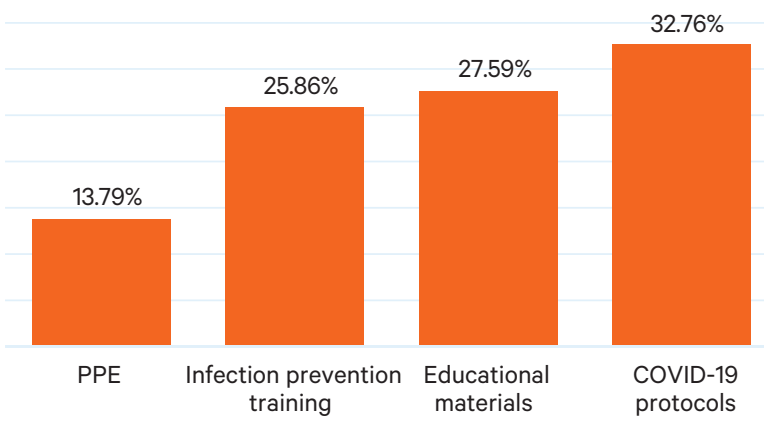

\section{Reassuring Parents and Schools}

About $36 \%$ of dental directors reported that updates were made to the parent consent forms because of the COVID-19 pandemic. The changes included information about how and where oral health programs were conducted. Information was shared on infection prevention guidelines provided by the Organization for Safety Asepsis and Prevention (OSAP) and COVID-19 related guidelines provided by CDC on social distancing, wearing a mask, and COVID-19 symptom checks.

About $40 \%$ of the dental directors indicated the SBOPHs prepared new communication materials to engage or inform schools/parents about the safety of these programs during the COVID-19 pandemic. These materials included a COVID-19 safety flyer, a safety brochure to encourage dental sealants despite COVID-19 concerns, social media flyers promoting a return to dental care, a Q\&A sheet from the school nurse, and flyers reiterating the importance of maintaining regular oral health care for students during the pandemic. About $40 \%$ of dental directors said that communication documents were not evaluated for cultural appropriateness.

The schools used various methods to distribute these communication documents to parents. Paper flyers remained the top choice for sending information to parents. Some schools used technology such as QR codes, social media, Zoom classes, and text messages to provide documents. About $20 \%$ posted the materials on their schools' websites.

\section{Distribution of Communication Materials to Parents}
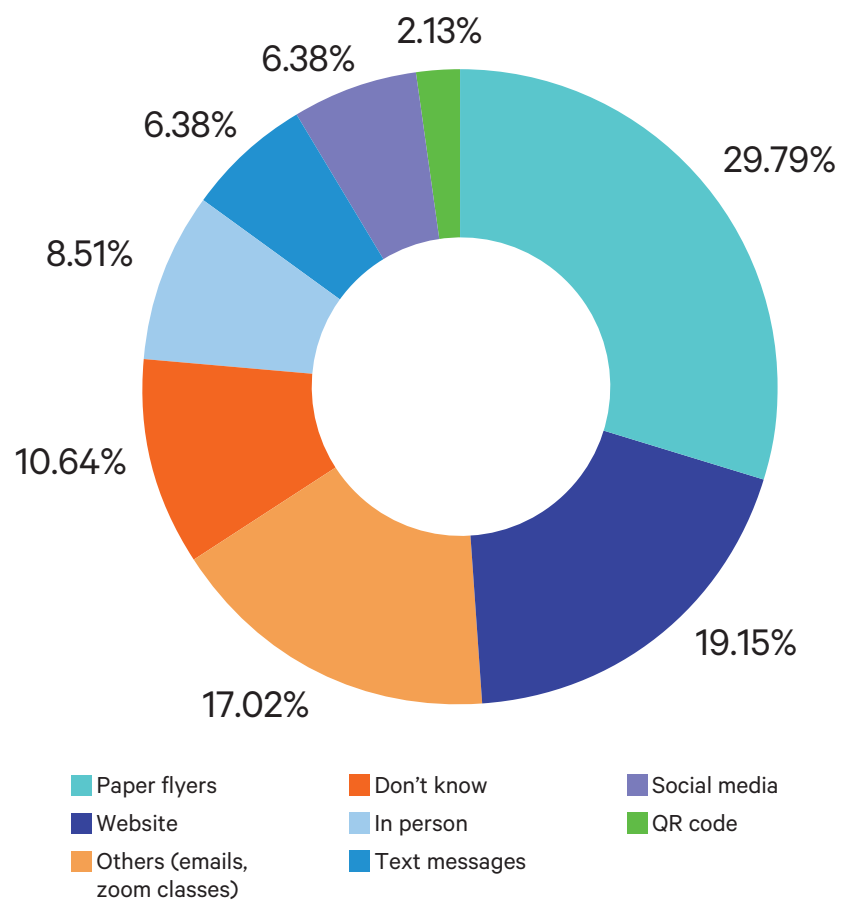

- Social media Q QR code 


\section{Student Population Characteristics}

Dental directors reported that the overall Medicaid eligibility for the students increased by $45 \%$ in their states, but utilization only increased by 3.2\% from the 2019-2020 school year to the 2020-2021 school year. Medicaid eligibility did not decrease, but utilization decreased by $49 \%$ in students from the 2019-2020 school year to the 2020-2021 school year. It is important to note that several dental directors did not report the Medicaid eligibility or utilization for students; $39 \%$ did not know the change in Medicaid eligibility, and 45\% did not know about the shift in Medicaid utilization.
Only $21 \%$ of dental directors provided the racial/ethnic percentage breakdown for their student populations receiving oral health services from the programs that were administered or funded by the state/territorial oral health program in 2020. In comparing the racial/ethnic breakdown provided by the dental directors to 2010 U.S. Census data, these SBOHPs provided services mainly to the ethnic minority groups within each of these states. They successfully targeted populations with oral health disparities.

\section{Shift in Medicaid Eligibility and Utilization from 2019-2020 to 2020-2021 School Year}

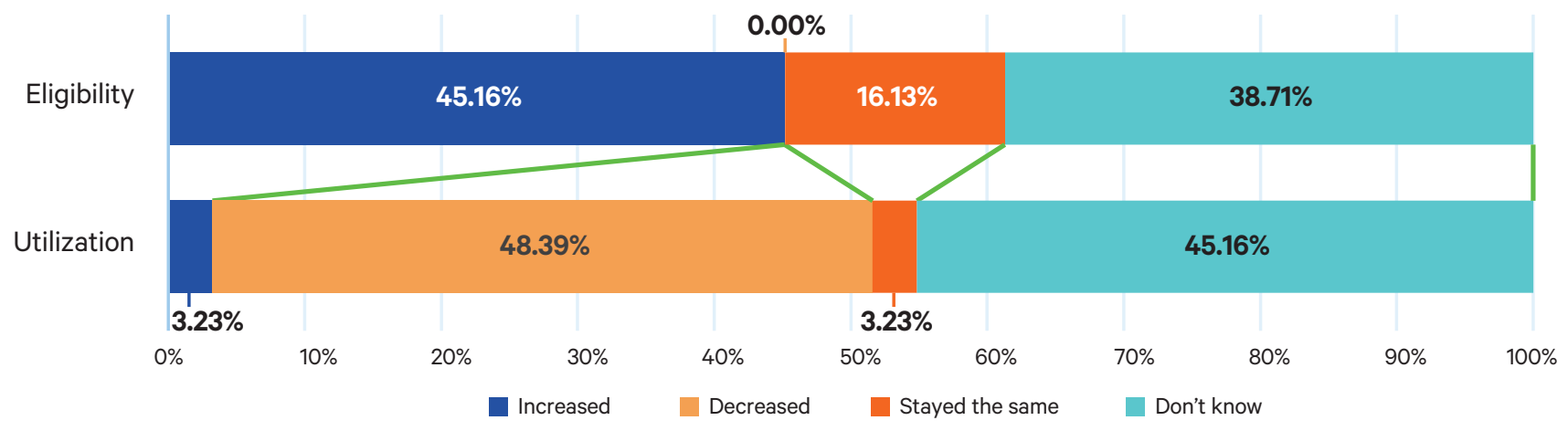

Table 1: Percent of student populations who received oral health services from the programs that were administered or funded by the state/ territorial oral health program in 2020. The numbers in the parentheses are the percentages of the population racial/ethnic breakdown in each state.

\begin{tabular}{|c|c|c|c|c|c|c|c|}
\hline & $\begin{array}{l}\text { Hispanic/ } \\
\text { Latin } \\
(\%)\end{array}$ & $\begin{array}{l}\text { White/ } \\
\text { Caucasian } \\
\text { (\%) }\end{array}$ & $\begin{array}{l}\text { Black/African } \\
\text { American (\%) }\end{array}$ & $\begin{array}{l}\text { Asian/Asian } \\
\text { American } \\
(\%)\end{array}$ & $\begin{array}{c}\text { American } \\
\text { Indian/ } \\
\text { Alaska Native } \\
(\%)\end{array}$ & $\begin{array}{c}\text { Hawaiian/ } \\
\text { Pacific Islander } \\
\text { (\%) }\end{array}$ & $\begin{array}{c}\text { Multiracial } \\
(\%)\end{array}$ \\
\hline lowa $^{2}$ & $16.3(6.3)$ & $70.5(85)$ & $7.6(4.1)$ & $1.9(2.7)$ & $0.3(0.5)$ & 0 & 0 \\
\hline Maryland $^{3}$ & $30(10)$ & $15(50)$ & $40(31.1)$ & $5(6.7)$ & $0(0.6)$ & $0(0.1)$ & 0 \\
\hline New Mexico ${ }^{4}$ & $55(49)$ & $30(36.8)$ & $5(2.6)$ & $0(1.8)$ & $10(11)$ & 0 & 0 \\
\hline Alabama $^{5}$ & $8(4.6)$ & $55(65.3)$ & $33(26.8)$ & $1(1.5)$ & $1(0.7)$ & 0 & 2 \\
\hline $\begin{array}{l}\text { Commonwealth } \\
\text { of Northern } \\
\text { Mariana Islands } \\
(\mathrm{CNMI})^{6}\end{array}$ & $1(0.5)$ & 2 (3.7) & $1(1)$ & $36(48.2)$ & 0 & $40(33.6)$ & $20(13)$ \\
\hline Ohio ${ }^{7}$ & $5(4)$ & $58(78.4)$ & $28(13)$ & $2(2.5)$ & $1(0.3)$ & 0 & 0 \\
\hline Missouri ${ }^{8}$ & $4.2(4)$ & $81.16(79.1)$ & $7.55(12)$ & $1.52(2.2)$ & $0(0.6)$ & $0(0.2)$ & 4.81 \\
\hline
\end{tabular}





\section{References}

1. Myechia Minter-Jordan, New DentaQuest Why We Must Preserve School-Based Oral Care for Children. San Francisco: California Oral Health Technical Assistance Center; September 17, 2020. Accessed April 14, 2021, https://oralhealthsupport.ucsf.edu/news/new-dentaquestwhy-we-must-preserve-school-based-oral-care-children.

2. U.S. Census Bureau. Quick Facts lowa. Population Estimates July 1, 2019 Accessed April 14, 2021, https://www.census.gov/quickfacts/IA

3. U.S. Census Bureau. Quick Facts Maryland. Population Estimates July 1, 2019. Accessed April 14, 2021, www.census.gov/quickfacts/MD

4. U.S. Census Bureau. Quick Facts New Mexico. Population Estimates July 1, 2019. Accessed April 14, 2021, www.census.gov/quickfacts/NM.

5. U.S. Census Bureau. Quick Facts Alabama. Population Estimates July 1, 2019. Accessed April 14, 2021, www.census.gov/quickfacts/AL.

6. Justyna Goworowska and Steven Wilson, U.S. Population Trends for the U.S. Island Areas: 2000 to 2010. Special Studies. Current Population Reports. Washington, D.C.: U.S. Department of Commerce, U.S. Census Bureau, April 2015. https://doi.opengovibmcloud.com/sites/doi.gov/ files/uploads/Census-Bureau_Pop-Trends-2000-10-in-Insular-Areas_ Apr2015.pdf.

7. U.S. Census Bureau. Quick Facts Ohio. Population Estimates July 1, 2019. Accessed April 14, 2021, www.census.gov/quickfacts/OH.

8. U.S. Census Bureau. Quick Facts Missouri. Population Estimates July 1, 2019. Accessed April 14, 2021, www.census.gov/quickfacts/MO

\section{Methodology:}

ASTDD organized a COVID-19 School-Based Programs Workgroup that included state dental directors, staff, and consultants of the CareQuest Institute on Oral Health. The workgroup identified emerging issues associated with conducting oral health services in schools during the COIVD-19 pandemic. A subcommittee of the workgroup developed a survey asking the state and territorial dental directors in all the 50 states, District of Columbia, and the U.S.affiliated territories to share information about their schoolbased programs.

The survey was sent to all state and territorial dental directors in mid-February 2021 and requested a response in 3 weeks. The results of this survey will be presented in aggregate in a report disseminated by ASTDD and the CareQuest Institute on Oral Health. Permissions were obtained from the eight states to present identifiable data related to the race/ethnicity of their students. The survey implementation was done using Qualtrics software. All data were aggregated and analyzed using Qualtrics outputs and Excel. 


\section{CareQuest Institute for Oral Health}

CareQuest Institute for Oral Health is a national nonprofit championing a more equitable future where every person can reach their full potential through excellent health. We do this through our work in grantmaking, research, health improvement programs, policy and advocacy and education as well as our leadership in dental benefits, care delivery and innovation advancements. We collaborate with thought leaders, health care providers, patients and local, state and federal stakeholders, to accelerate oral health care transformation and create a system designed for everyone. To learn more, visit carequest.org.

\section{Association of State and Territorial Dental Directors}

The Association of State and Territorial Dental Directors (ASTDD) is a national non-profit organization representing the directors and staff of state public health agency programs for oral health. It was organized in 1948 and is one of 20 affiliates of the Association of State and Territorial Health Officials (ASTHO). ASTDD formulates and promotes the establishment of national dental public health policy, assists state dental programs in the development and implementation of programs and policies for the prevention of oral diseases; builds awareness and strengthens dental public health professionals' knowledge and skills by developing position papers and policy statements; provides information on oral health to health officials and policy makers, and conducts conferences for the dental public health community. To learn more, visit astdd.org. 